is possible that 4 -shaped masking functions manifest themselves over a limited range of

$\Delta t$ and that $-\Delta t=0$ must be tested to disclose them. Another difference is that in Experiment 3 the target was presented at exposure levels well above its absolute detection threshold: as in Experiment 2, the target exposure had sufficient luminance. duration, and contrast to be correctly identified about $80 \%$ of the time when target and mask were exposed at $-\Delta t=0$ and. as ascertained by pilot work, could be reported $100 \%$ of the time when exposed without a mask. On the other hand, Haber (1968) used a target exposure which allowed the target to be reported correctly only $80 \%$ of the time when presented without an accompanying masking flash and could be said to be near threshold. The effect of simultaneous exposure of target and mask fields is to reduce the physical contrast of stimuli in either field. It is likely that the reduction in the target's physical contrast resulted in the poor performance of Haber's Os at $-\Delta t=0$, while in Experiment 3 the target's contrast at simultaneous exposure was sufficient to permit good recognition scores.

A tentative conclusion is indicated by this analysis. If a target is readily masked at $-\Delta t=0$. by physical contrast reduction, it may be that whatever masking effects are operating at longer $-\Delta$ ts (say, $-20<\Delta \mathrm{t}<0$ ) will produce less profound effects. The end result will be an improvement in recognition at $-\Delta t$ values greater than zero when the target is difficult to recognize at simultaneous exposure, and a monotonic masking function will be manifest. It would seem, then, that a requirement for obtaining nonmonotonic, or U-shap2d, masking functions is that the target be above threshold in the absence of a mask and not be greatly susceptible to masking at $-\Delta \mathrm{t}=0$.

The requirement that the target be above threshold and also be partially resistent to masking at $-\Delta t=0$ in no way vitiates the assumptions of the luminance-summation model of masking. This model only stipulates that maximum masking is obtained at $-\Delta t=0$, without regard for the absolute level of masking obtained at $-\Delta t=0$. It may be that the limit beyond which luminance-summation explanations no longer hold can be defined by employing target exposures that are above threshold without a mask and only slightly susceptible to masking at $-\Delta t=0$.

\section{REFERENCES}

ERIKSEN, C. W. Temporal luminance summation effects in backward and forward masking. Perception \& Psychophysics, 1966, 1 , 87.92.

HABER, R. N. A replication and extension of the
Eriksen and Steffy (1964) experiment on short-term visual storage. Perception \& Psychophysics. 1968. 4, 341-343.

KAHNEMAN, D. Wethod, findings and theory in studies of visual masking. Psychological Bulletin, 1968, 70, 404-425.

PURCELL, D. G., STEWART, A. I., \& DEMBER, W. N. Backward masking: Facilitation through increased target-field luminance and duration. Psychonomic Science, $1969,15,87-88$.

RAAB, D. H. Backward masking. Psychological Bulletin, 1963, 60, 118-129.

SPENCER, T. J., \& SHUNTICH, R. Evidence for an interruption theory of backward masking. Paper presented at the meetings of the Midwestern Psychological Association, 1970.

THOMPSON, J. H. What happens to the stimulus in backward masking? Journal of Experimental Psychology, 1966, 71, 580-586.

WEISSTEIN, N. A Rashevsky-Landahl neural net: Simulation of metacontrast. Psychological Review, 1968, 75, 494-521.

WEISSTEIN, N. U-shaped and W-shaped masking functions obtained for monoptic and dichoptic disc-disc masking. Paper presented at the meetings of the Midwestern Psychological Association, 1970 .

\title{
Self-esteem and balance with impersonal attitude objects
}

\author{
W. PETER ARCHIBALD \\ University of Michigan, Ann Arbor, Mich. 48104
}

Previous research demonstrates that cognitive-consistency predictions should take Ss' self-esteem into account, for what is consistent for those with positive self-esteem may be inconsistent for those with negative self-esteem. In most studies the attitude object is the $\mathrm{S}$ himself, so that liking for others with whom one agrees is balancing for all Ss. For Ss with negative self-esteem, however, liking for others with whom one disagrees should be balancing when the object of disagreement is an impersonal one. In the present experiment $\mathrm{Ss}$ differing in selfesteem were presented with three levels of agreement-disagreement over the war in Vietnam, with three different hypothetical others. Contrary to the hypothesis, a Self-Esteem by Agreement interaction was not obtained, the only strong and consistent effect being a main effect for agreement. The results are discussed in terms of the limited range of the self-esteem variable and the questionable validity of the hypothesis.

The results of several experiments demonstrate that cognitive-consistency predictions should take Ss' self-esteem in to account, for what is consistent for those with positive selfesteem may be inconsistent for those with negative self-esteem. According to balance theory, for instance, the $S$ who dislikes himself should like others who dislike him and dislike others who like him (Deutsch \& Solomon, 1959; Jones \& Schneider, 1968; Wiest, 1965), although results have not always supported this contention (Dickoff, 1961; Jones, 1966; Walster, 1965).

When the attitude object is the $\mathrm{S}$ himself, as in the above example, liking others with whom one agrees and disliking others with whom one disagrees should 
produce balance for all Ss. When the attitude object is an impersonal object, however, liking others with whom one disagrees and disliking others with whom one agrees may very well be balanced for the $S$ with low or negative self-esteem. In addition to seeing negative objects linked with himself, another negative cognitive entity, the $S$ with low self-esteem may deduce from the disagreement that the other will dislike him (Aronson \& Worchel, 1966) and take this as further confirmation for his self-image.

None of the above mentioned studies permit a test of this hypothesis. All except the Jones (1966) and the Jones \& Schneider (1968) studies explicitly use the $S$ himself as the attitude object, while the latter studies do not allow one to decide whether the object is an impersonal one, the $\mathrm{S}$ himself, or both. In these studies Ss do not evaluate themselves directly; they evaluate their judgments of paintings. Similarly, others do not evaluate Ss directly; they evaluate a Ss' judgments, so that there could actually be agreement on the worth of a painting but disagreement on the judgmental abilities of the $S$. Finally, since Ss evaluate others' judgments and not others per se, they could think lowly of the others' judgmental abilities but still like them. The relative unimportance of artistic judgments for the average college sophomore may have increased the likelihood of these things occurring.

Suggestive evidence for the hypothesis is contained in a survey study by this author (in preparation), where the attitude object was the war in Vietnam. In that study the more uncertain respondents were of their own attitudes, the less likely they were to devalue the views of groups with whom they perceived disagreement. In the present study agreement is manipulated rather than left to $\mathrm{Ss}^{\prime}$ memories, and self-esteem and liking for others are measured directly.

\section{PROCEDURE}

The Ss consisted of 38 students of both sexes in introductory psychology and sociology courses at the University of Michigan.

Ss were asked by one $E$ to fill out a self-esteem instrument. This instrument was a modification of Bills's (undated). It used the same format, but item content was altered somewhat to acquire equal numbers of positive and negative adjectives and equal numbers relating to individualand other-oriented behavior. Split-half reliability coefficients were .79 and .81 , respectively, for simple summation and discrepancy scores, and the latter scores correlated .62 with each other.

Approximately $1 \frac{112}{2}$ weeks later, a second $\mathrm{E}$ administered an "opinion" questionnaire on the war in Vietnam. In it Ss werc asked which course they would like the United States to take in Vietnam. They could choose one of four strategies, which were, in abbreviated form, "Rapid and immediate military escalation...." "Gradual military escalation...," "Gradual military de-escalation ...," and "Rapid and immediate de-escalation..."

In the rest of the items, all Ss were asked to consider four hypothetical social situations involving themselves and another person whom they had met for the first time. In each of these situations, the hypothetical other was described as having one of the four different positions on the Vietnam issue. This allowed for at least three levels of agreement for each $S$, since one other would agree with him, one would disagree one step in the opposite direction, and one would disagree two steps in the opposite direction. After learning each other's opinions, Ss were asked to assume that they would not be able to change the other's opinion, nor did the other expect to change the S's opinion. (This was intended to rule out these means of reducing imbalance.) Ss were then asked to estimate, using 7-point bipolar scales, how much they would like the specific other, how much they would like to meet that other, and how much they would like the other as a friend.

At the end of the second session, the $E$ provided a complete explanation of the experiment and discussed the reasons for the deception. No $S$ had seen any connection between the two phases of the experiment.

\section{RESULTS AND DISCUSSION}

Self-esteem scores were split at the medians to permit analyses of variance. Since the results for all three measures of attraction toward others were similar, the three indices were combined for the analyses presented here. The results are summarized in Table 1. Data were analyzed by two-way analyses of variance with replications. The results indicate significant main effects for agreement $(p<.001$ and

\section{Table 1}

Rated Attractiveness of Others as a Function of Self-Esteem and Degree of Agreement-Disagreement

\begin{tabular}{|c|c|c|c|}
\hline & $\begin{array}{c}\text { Agree- } \\
\text { ment }\end{array}$ & $\begin{array}{c}\text { Medium } \\
\text { Disagtee- } \\
\text { ment }\end{array}$ & $\begin{array}{l}\text { Strong } \\
\text { Dis- } \\
\text { agreement }\end{array}$ \\
\hline \multicolumn{4}{|l|}{ High Self-Esteem } \\
\hline Summation & 7.8 & 11.3 & 12.8 \\
\hline Discrepancy & 9.3 & 10.3 & 12.5 \\
\hline \multicolumn{4}{|l|}{ Low Self-Esteem } \\
\hline Summation & 8.2 & 10.2 & 12.9 \\
\hline Discrepancy & 7.7 & 11.1 & 13.4 \\
\hline
\end{tabular}
attractiveness. $p<.01)$, showing the standard balance effect of liking those with whom one agrees more than those with whom one disagrees. There were no interactions between self-esteem and agreement, however. The only self-esteem effect is a main effect on the discrepancy measure, such that Ss low in self-esteem reacted more negatively to disagreement than did $\mathrm{Ss}$ high in self-esteem $(\mathrm{p}<.025)$. Since the two self-esteem measures were imperfectly correlated, a third analysis was performed using only Ss who scored high or low on both measures. This analysis, which reduced cell frequencies from 19 to 12 , erased the self-esteem effect but otherwise did not affect the results.

In this study, therefore, Ss low in self-esteem are not more likely than those high in self-esteem to prefer disagreement and not less likely to prefer agreement on impersonal objects. In fact, the opposite may be the case, if the one self-esteem effect is reliable.

One difficulty with the design is the restricted range of the self-esteem scores: On the simple summation measure only one score was in the lower quarter of the potential range; on the discrepancy measure there were no scores below the theoretical midpoint. This suggests that the hypothesis may not have received a fair test. In future research self-esteem should be manipulated or Ss should be selected to represent a wider range of self-esteem. Nevertheless, the results of the present experiment throw doubt on the validity of the hypothesis.

\section{REFERENCES}

ARONSON, E., \& WORCHEL, P. Similarity versus liking as determinants of interpersonal attractiveness. Psychonomic Science, 1966, 5, 157-158.

BILLS, R. E. Index of adjustment and values. Manual. University of Alabama. Mimeographed. Undated.

DEUTSCH, M., \& SOLOMON, L. Reactions to evaluations by others as influenced by self-evaluation. Sociometry, 1959, 22, 93-112.

DICKOFF, H. Reactions to evaluations by another person as a function of self-evaluation and the interaction context. Unpublished PhD dissertation, Duke University, 1961.

JONES, S. C. Some determinants of interpersonal evaluating behavior. Journal of Personality \& Social Psychology, 1966, 3, 397-403.

JONES, S. C., \& SCHNEIDER, D. J. Certainty of self-appraisal and reactions to evaluations from others. Sociometry, 1968, 31, 395-403.

WALSTER, E. The effect of self-esteem on romantic liking. Joumal of Experimental \& Social Psychology, 1965, 1, 184-197.

WIEST, W. W. A quantitative extension of Heider's theory of cognitive balance applied to interpersonal perception and self-esteem. Psychological Monographs, 1965, 79 (Whole No. 607). 